\title{
A Scanning Electron Microscopic Study of Differentiation of the Digital Pad in Regenerating Digits of the Kenyan Reed Frog, Hyperolius viridiflavus ferniquei 1,2
}

\author{
CHRISTINA M. RICHARDS, BRUCE M. CARLSON, THOMAS G. CONNELLY, \\ SHERRY L. ROGERS AND ELIZABETH ASHCRAFT \\ Departments of Zoology and Anatomy and Center for Human Growth and Development, \\ University of Michigan, Ann Arbor, Michigan 48109
}

\begin{abstract}
Newly metamorphosed Kenyan reed frogs, Hyperolius viridiflavus ferniquei, are able to regenerate amputated digits. The terminal digital pad is also completely reformed. Differentiation of the regenerating digital pad was studied by scanning electron microscopy. External differentiation of the digital pad began late in the second postamputational week with the appearance of small patches of specialized epidermal cells on the ventral surface of the regenerating digit. The differentiation of the pad spread out radially until late in the fourth week, when its overall shape approximated that of the normal digital pad. The appearance of patches of digital pad epidermis on the ends of spike regenerates arising from the forearm was also confirmed.
\end{abstract}

Postmetamorphic Kenyan reed frogs, $H y$ perolius viridiflavus ferniquei, are able to regenerate amputated digits (Richards et al., '75) so well that the regenerates are virtually indistinguishable from normal ones. Hyperolius belongs to the family Hyperoliidae, all members of which have expanded digital pads. Most members of the closely related family Rhacophoridae also have well developed toe pads. These two families, referred to jointly as "old world tree frogs", are closely related to the Ranidae, a family with worldwide distribution but whose members show digital epidermal specializations. These three families have been grouped by Duellman ('75) into the superfamily Ranoidea and are generally regarded as "advanced" frogs. Ranids are well known as non-regenerators (Schotté and Harland, '43; Rose, '44; Polezhaev, '45), and it is of interest that members of the same superfamily should respond to amputation in such diverse manners.

Other major groups possessing digital pads are the Hylidae (new world tree frogs), Leptodactylidae and Dendrobatidae, all belong. ing to the superfamily Bufonoidea, and the family Microphylidae in its own superfamily Microhyloidea. Phylogenetic relationships among the amphibia are extremely controversial (Duellman, '75); nevertheless it is clear that regardless of which system of classifi- cation is followed, expanded digital pads occur in widely divergent groups. The natural regenerative capacity of many of these species has not been investigated.

The expanded digital pad possesses a highly specialized epidermis (Ernst, '73; Welsch et al., '74), which is remarkably similar from group to group among the anurans which have pads (Nobel and Jaeckle, '28). Digital pads presumably assist Hyperolius in exploiting the habitat afforded by the tall reeds and other vegetation on which they cling.

The distinctive surface morphology of the digital pad provides an excellent means for following the time course and topography of differentiation of this structure during regeneration of the digit. Because of its apical position, the pad also serves as a potentially useful morphogenetic marker in experimental studies of limb and digital regeneration in Hyperolius. The present study was designed to determine the normal pattern of surface development of the digital pad on regenerating forearms and digits. This process was studied with the scanning electron microscope (SEM).

\section{MATERIALS AND METHODS}

This investigation was carried out on 121

\footnotetext{
Contribution number 78 from the Amphibian Facility.

${ }^{2}$ Supported in part by a grant from the Muscular Dystrophy Asso. ciations, Inc. and NIH Grants HD08150 and RR 0572 .
} 


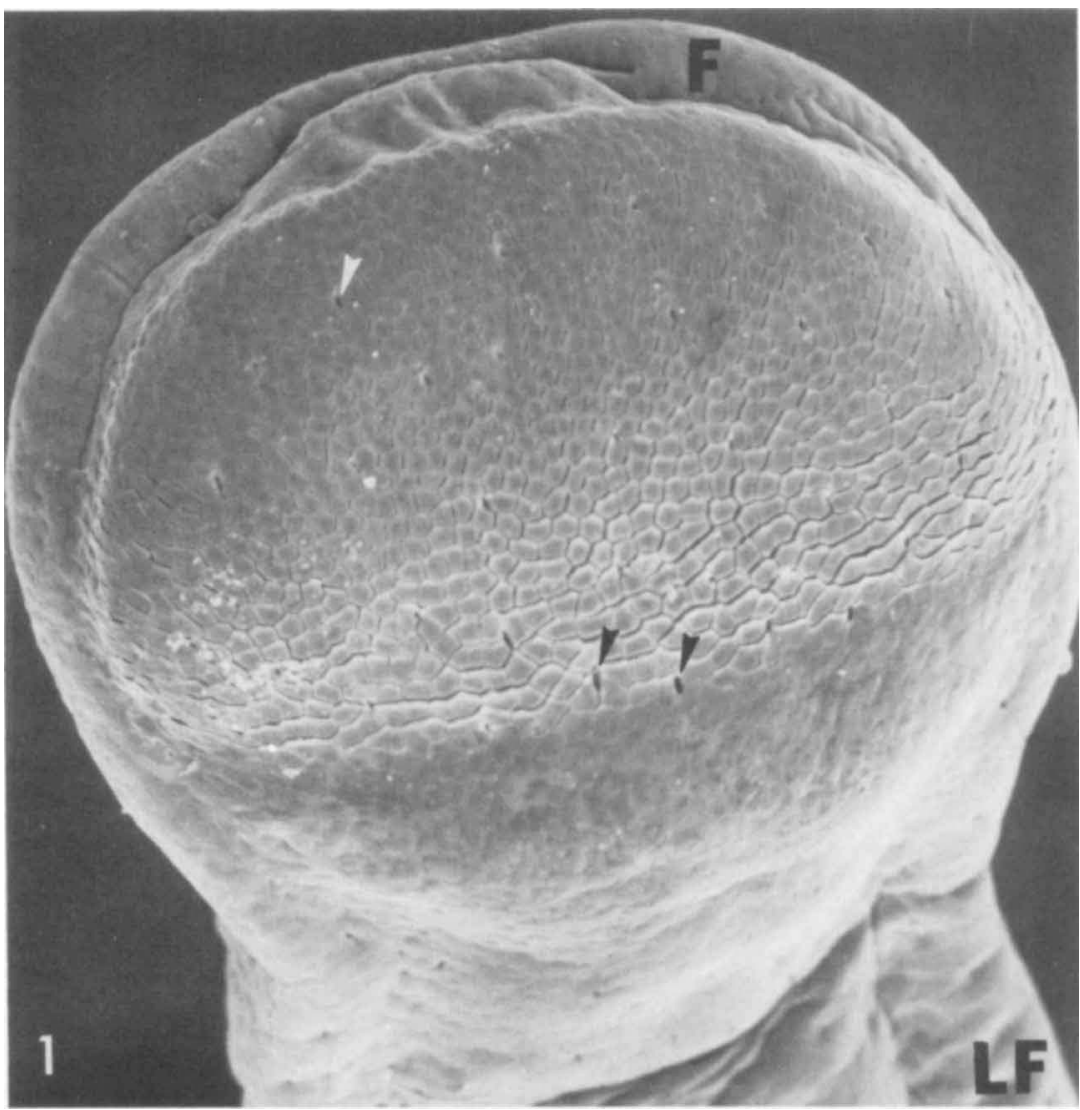

Fig. 1 Normal digital pad of 52 day post-metamorphic Hyperolius. The last segment of the digit is viewed from the ventral surface. The specialized epidermal cells of the pad occupy a roughly hemispherical area. Proximally they gradually merge into normal surface epithelium. Around the distal and lateral margins of the pad is a deep groove that delineates the pad. The groove is interrupted by a distal frenulum $(\mathrm{F})$. Ducts of the mucous glands empty to the surface as irregularly distributed pores (arrows). Lateral skin folds (LF) continue from the proximal regions of the digit around the pad and meet at the apex. $\times 180$.

Kenyan reed frogs (Hyperolius viridiflavus ferniquei) that were raised from a single batch of eggs at the Amphibian Facility at The University of Michigan. After metamorphosis animals were housed ten to a plastic box $4 \times 5$ $\times 7^{\prime \prime}$ lined with a wet paper towel. Boxes were changed three times a week. Frogs were fed crickets dusted with a vitamin-mineral supplement (Pervinal) daily.

All amputations were performed two days after tail resorption. The frogs ranged from $15-19 \mathrm{~mm}$ in snout-vent length with a mean of $16.9 \mathrm{~mm}$. There were two series of amputations. In one, the third digit on each hand was amputated through the middle of the second phalanx. In the other series one arm was amputated midway through the forearm. Bilateral arm amputations were not done be- cause this gravely reduced the ability of the frogs to capture live food, resulting in disturbance to their overall growth.

One hundred frogs were used in the digital amputation series. Regenerates from two animals were fixed each day from 1 to 40 days after amputation. Other animals were killed at irregular intervals until 95 days postoperatively. For each animal, one hand bearing the regenerate was fixed in $2.5 \%$ glutaraldehyde in $0.1 \mathrm{M}$ cacodylate buffer $(\mathrm{pH} \mathrm{7.4)}$ for SEM, and the other hand was fixed in Bouin's fluid for a histological control.

Twenty-one frogs were used in the limb amputation series. Regenerates were fixed as described above for SEM at irregular intervals fom 8 to 83 days.

Regenerates prepared for SEM were dehy- 
drated through a graded series of alcohols, to absolute ethanol. Tissues were placed directly into a Denton vacuum critical point drying apparatus. Specimens were mounted on aluminum stubs with silver paint or Duco cement. They were subsequently coated with gold and examined in a JSM-U3 SEM at the University of Michigan Scanning Electron Microscope Facility.

\section{RESULTS}

\section{The normal digital pad (fig. 1)}

The surface morphology of the normal digital pad is dominated by a roughly hemispherical area of specialized epidermis, in which the flat hexagonally-shaped surfaces of the cells stand out sharply, as though set in a mosaic (fig. 2). The epidermal cells are not in contact with their neighbors, but are separated from one another by deep spaces. Ducts of the mucous glands come to the surface of the pad as unspecialized pores (fig. 2) which are scattered irregularly throughout the pad.

Peripheral to the rounded apical and lateral borders of the pad is a well-defined groove (fig. 1) that separates the pad epidermis from the pronounced fold that runs along the lateral borders of the entire digit and crosses the apex of the digit. In most pads a frenulum-like structure (fig. 1) breaks the continuity of the groove, usually at some point near the apex of the pad. The epidermis lining the groove may have the surface features of normal epidermis, but not uncommonly the cells are densely covered with long microvillous structures. Within the groove, the epidermis is often thrown into an irregular fold.

Along the semicircular groove, the specialized cells of the pad change rather sharply into the cell type characteristic of the groove. In contrast, the cells along the proximal straight margin of the pad undergo a gradual transition from specialized to normal epidermal morphology. In some cases, the groove continues around the proximal flat border of the pad. In others the groove stops at the proximal part of the lateral boundary of the pad.

\section{The regenerating digit}

The amputated digit is quickly healed over with epidermis. During the first ten days after amputation, a smooth epidermis covers the rounded tip of the blastema. The lateral digital folds lose their prominence at the amputation surface and merge into the smooth sur-

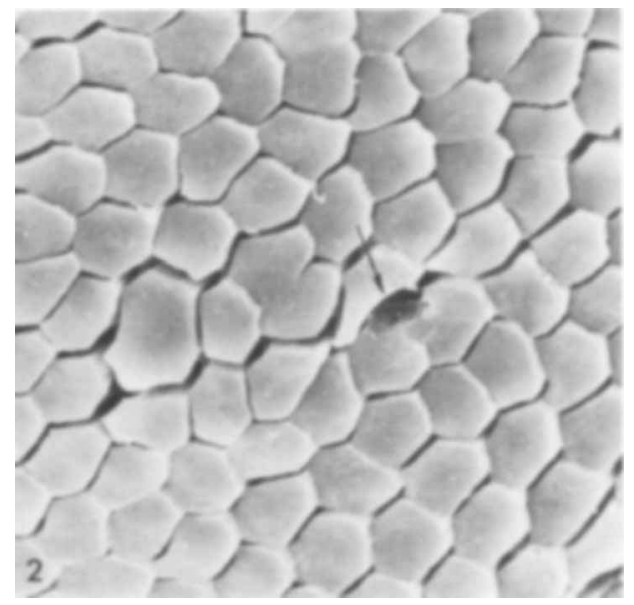

Fig. 2 Higher power view of digital pad epidermis, showing the pore of one mucous gland (arrow). The surface of the epidermal cells are smooth. A well-defined space separates each cell from its neighbors. $\times 674$.

face of the blastema (fig. 3). Although an apical thickening of the wound epidermis is seen in histological sections (Richards et al., '75: figs. 5, 6), examination of the blastemal surface by SEM alone does not suffice to demonstrate the thickening. This is also characteris. tic of regenerating limbs of the newt (Tank, Carlson and Connelly, unpublished) in which the boundaries of the pronounced apical epidermal thickening cannot be defined by scanning of the surface alone. An apical epidermal ridge of the type found in outgrowing limbs of higher vertebrates is not present.

Starting with the twelfth and thirteenth day, small patches of cells with the surface characteristics of pad cells begin to appear on the ventral surface of the regenerating digit (fig. 4). During the first days after their appearance, the differentiating epidermal cells of the pad gradually merge into the surrounding epidermis on all sides, while those at the center of the newly forming pad resemble very closely those of the mature digital pad (fig. 5). The presence of pores among the differentiated epidermal cells of the pad attests to the formation of mucous glands in the deeper tissues. Our previous histological study (Richards et al., '75: figs. 8, 9) showed that mucous glands began to form during the fourth postamputational week. The groove that surrounds the mature pad has not yet begun to form. As the regenerate bearing the early pad continues to grow out, the lateral digital folds begin to re-form distally, produc- 
ing a continuous elevation around the apex of the regenerate (fig. 4).

Toward the end of the third week, the groove becomes defined around the convex surface of many of the digital pads (fig. 6). At this time, the pad is commonly kidney beanshaped, with the proximal border being concave rather than straight as in the mature pad.

Except for its overall shape (fig. 7), the regenerating digital pad late in the fourth week is very similar to the mature pad. The cells within the circumferential groove, which is often well established, are distinguished by their surface microvilli (figs. 8, 9), whereas those of the fold distal to the groove are typical general ventral epidermis of the digit.

After the first month the shape of the regenerating pad is relatively stable. The primary morphological changes are the gradual flattening of the proximal base of the pad and the overall expansion of the pad past the normal lateral margins of the digits.

\section{The regenerating limb}

It was reported earlier (Richards et al., '75) that amputated forearms of Hyperolius also regenerate, although commonly a spike regenerate forms rather than a complete limb with a hand and digits. Despite the lack of distal differentiation of skeletal parts, areas of digital pad epithelium often appear, but the overall shape of the area covered by pad epithelium could not be readily determined from the examination of sectioned material.

The present SEM study has confirmed the presence of pad epithelial cells in about half of the regenerates examined. Occasional pores of mucous glands are seen among the pad epithelial cells, corresponding to the sparse mucous glands previously seen in hypomorphic limb regenerates (Richards et al., '75: their fig. 19). Despite the presence of most of the histological components of the pad, overall morphogenesis is poor and the "pad" consists of an irregularly shaped patch (patches) of pad epithelial cells. This circumferential groove, which surrounds digital pads, has not been seen on spike regenerates of the forearm: In summary, despite advanced cellular and, to some extent, tissue differentiation, overall morphogenesis of the terminal pad as an entire organ is poor.

\section{DISCUSSION}

Our previous histological study (Richards et al., '75) of digital regeneration in Hyperolius led us to conclude that histologically the regenerated digital pad is restored to a normal morphology. The present SEM study has shown that the overall shape and surface specializations of the regenerated digital pad are also completely restored to normal.

There was a good correlation between histological and SEM observations with respect to the time of differentiation of various components of the digital pad. By the end of the second week the first traces of surface differentiation of epidermal cells of the pad are evident. Within a few days the pores of the mucous glands can also be seen among the specialized epidermal cells. The epidermal cells of the pad differentiate first at one focus rather than simultaneously throughout the pad. Then it appears that epidermal differentiation spreads out radially from this primary focus. Although it is difficult to predict mechanisms from the examination of a series of static morphological preparations, the primary morphogenetic event seems to be the one leading to the appearance of the first group of pad cells. It is not unlikely that once the primary focus of pad cells is established, formation of the remainder of the pad is influenced by the primary pad cells. With the limited data at hand, further speculation on the details of the morphogenetic mechanisms is not profitable. Nothing can be said about the events leading to the formation of the deep circumferential groove that surrounds much of the digital pad.

SEM observations on regenerating limbs confirm the presence of digital pad epidermis at the apex of about half of the morphologically incomplete spike regenerates. The poor terminal morphology of the regenerates as a whole was reflected in the epidermis. Although the individual epidermal cells were of typical morphology, their distribution was highly irregular. These cells tended to be present in patches, often with areas of normal epidermis interposed between patches of pad epidermis. The extent to which these abortive "digital" pads were useful to the frogs is questionable because the growth of frogs with one amputated forearm was substantially less than those with amputated digits (Richards et al., '75).

From our observations, it is evident that although the conditions at the tip of the regenerated spike are compatible with the cytodifferentiation of the specialized epidermal 
cells of the digital pad, they are not favorable for overall morphogeneis of the pad. This suggests that cytodifferentiation is controlled by a different set of mechanisms from that controlling morphogenesis of the pad. A major point for future investigation concerns the conditions compatible with the expression of pad characteristics in the digital epidermis of digital and especially forearm regenerates. A major question is whether an epimorphic field must be set up in order for the pad to form or whether an apical position of the wound epidermis is all that is required. Another question of particular relevance to hypomorphic forearm regenerates concerns the proximodistal dissociation of levels between the specialized apical epidermial pad cells and the underlying tissues. Previous work on both invertebrates (Bohn, '70a,b; Bullière, '71) and vertebrates (Iten and Bryant, '75; Stocum, '75) has shown that intercalary regeneration is likely to fill in the missing levels between a distal limb segment and more proximal tissues. This work particularly in amphibians, applies primarily to subepidermal tissues. It remains to be seen whether intercalary regeneration would always be elicited to fill in the gap in proximodistal levels between a terminal epidermal segment and more proximal skeletal or soft tissues of a hypomorphic regenerate. The other option is that a hypomorphic spike regenerate contains all proximodistal levels in a compressed form and is also deficient in its cross-sectional dimensions.

Early digital regenerates do not possess an apical epidermal ridge, and although thickening of the apical epidermis is obvious in histological sections (Richards et al., '75), the outlines of the thickened area could not be discerned with SEM. From histological preparations, the thickening is more of a broad caplike shape, as described by Thornton ('65). The shape of the apical epidermis over digital blastemas has received scant attention in any regenerating form. Therefore there is no basis for comparison. The lateral folds along the normal digits of Hyperolius are so prominent during the later morphogenesis of the regenerating digit that their role in the regenerative process deserves further attention. Such folds are not unique to Hyperolius, but are found in many amphibians, both urodele and anuran. Observations in Hyperolius in captivity suggests that the lateral digital folds may play an accessory role in adhesion to smooth surfaces for the frogs are commonly seen resting vertically or upside down in plastic cages with their digits, arms and ventral body skin tightly flattened against the wall. Very rarely does the weight of the frog seem to be supported entirely by the digital pads alone.

The formation de novo of specialized apical structures in regenerating extremities of Hyperolius has a parallel in other regenerating structures. In lizards, Maderson ('71) has shown that three types of epidermal specializations (sense organs, pilose pads and holocrine secretory organs) normally found on the tails of Lygodactylus are perfectly restored on regenerated tails. He related the perfection of these regenerating specializations to selection for their functional significance. Likewise, new lateral line organs (neuromasts) are formed in regenerating tails of larval axolotls, even in the absence of the lateral line nerve (Jørgensen and Flock, '76). Rogal ('51) described the formation of nails at the end of atypical digit-like structures which are stimulated to grow from wrist level amputations in newborn rats. Thus, there appears to be a distinct tendency toward reforming functional apical specializations on regenerating extremities even though the form of the extremity itself may be imperfect.

\section{ACKNOWLEDGMENTS}

We wish to thank Doctor William Burkel for the use of this critical point drying apparatus and for advice on its use. All of the people at the University of Michigan Scanning Electron Microscopy Laboratory were most helpful in guiding us in the use of the instrument.

\section{LITERATURE CITED}

Bohn, H. 1970a Interkalare Regeneration und segmentale Gradienten bei den Extremitäten von Leucophaea-Larven (Blattaria). I. Femur und Tibia. Roux́ Arch. Entw.-mech., 165: 303-341.

$1970 \mathrm{~b}$ Interkalare Regeneration und segmen tale Gradienten bei den Extremitäten von Leucophaea-Larven (Blattaria). II. Cox und Tarsus. Devel. Biol., 23: 355-379.

Bullière, $D 1971$ Utilization de la régénération interclaire pour l'étude de la determination cellulaire au cours de la morphogénèse chez Blabera craniffer (Insecta Dictyoptère). Devel. Biol., 25: 672-709.

Duellman, W. E. 1975 On the classification of frogs. Univ. Kansas Museum Nat. History Occas. Papers, 42: 114.

Ernest, V. V. 1973 The digital pads of the tree frog, Hyla cinerea. I. The epidermis. Tissue and Cell, 5: 83-96.

Iten, L. E., and S. V. Bryant 1975 The interaction between the blastema and stump in the establishment of the ante- 
rior-posterior and proximal-distal organization of the limb regenerate. Devel. Biol., 44: 119-147.

Jörgensen, J. M.. and A. Flock 1976 Non-innervated sense organs of the lateral line: development in the regenerating tail of the salamander Ambystoma mexicanum. J. Neurocytol., 5: 33.41 .

Maderson, P. F. A. 1971 The regeneration of caudal epidermal specializations in Lygodactylus picturatus keniensis (Gekkonidae, Lacertilia). J. Morph., 134: 467478.

Noble, G. K., and M. E. Jaeckle 1928 The digital pad of tree frogs. A study of the phylogenesis of an adaptive structure. J. Morph 45: 259-292.

Polezhaev, L. V. 1946 The loss and restoration of regenerative capacity in the limbs of tailless amphibia. Biol. Rev., 21: 141-147.

Richards, C. M., B. M. Carlson and S. L. Rogers 1975 Regeneration of digits and forelimbs in the Kenyan reed frog Hyperolius viridiflavus ferniquei. J. Morph., 146: 431446.
Rogal, I. G. 1951 On the possibility of limb regeneration in rats (In Russian). Doklady Akad. Nauk SSSR, 78: 161166.

Rose, S. M. 1944 Methods of initiating limb regeneration in adult Anura. J. Exp. Zool., 95: 149-167.

Schotte, O., and M. Harland 1943 Amputation level and regeneration in limbs of late Rana clamitans tadpoles. J. Morph., 73: 329-361.

Stocum, D. L. 1975 Regulation after proximal or distal transposition of limb regeneration blastemas and determination of the proximal boundary of the regenerates. Devel. Biol., 45: 112.136.

Thornton, C. S. 1965 Influence of the would skin on blastemal cell aggregation. In: Regeneration in Animals and Related Problems. V. Kiortsis and H. A. L. Trampusch, eds. North-Holland Publ. Co., Amsterdam, pp. 33-40.

Welsch, U., V. Storch and W. Fuchs 1974 The fine structure of the digital pads of the rhacophorid tree frogs. Cell Tissue Res., 148: 407-416.

\section{PLATE 1}

\section{EXPLANATION OF FIGURES}

3 Nine-day digital regenerate (ventral view). The outgrowing blastema is covered by a smooth epithelium without a ridge. The lateral digital folds merge into the blastema, where they temporarily lose their identity. The level of amputation is indicated by an arrow. $\times 114$.

4 Sixteen-day digital regenerate (ventral view). Specialized pad epidermis (E) is beginning to differentiate on the ventral side of the regenerate. On all sides it merges gradually with normal epithelium. Although the lateral digital ridges are again becoming identifiable around the regenerate, a groove does not yet separate them from the developing pad. $\times 117$.

5 Higher power view of the epidermis of the developing digital pad shown in figure 4 . The individual epidermal cells seem to be fully differentiated despite the immature condition of the pad as a whole. $\times 480$.

6 Eighteen-day digital regenerate, showing reformation of the groove around the digital pad. $\times 120$. 

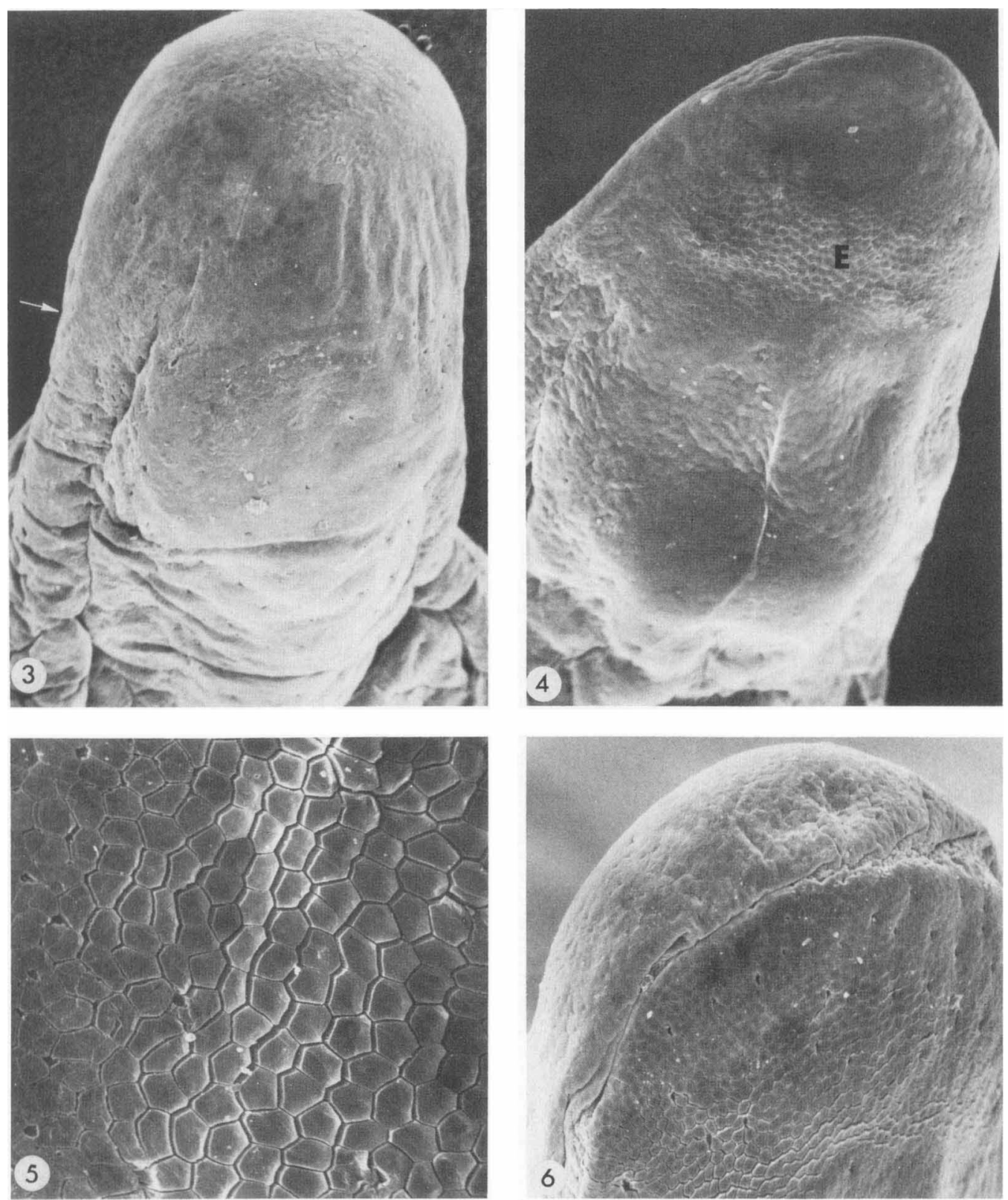
PLATE 2

EXPLANATION OF FIGURES

7 Ventral view of 26-day digital regenerate. The pad is roughly kidney bean-shaped, with a strongly convex proximal border. In this regenerate the circumferential groove around the regenerate is just beginning to form. $\times 108$.

8 Distal portion of digital pad in 25-day digital regenerate. The specialized cells of the pad abruptly shift to another type at the edge of the groove that surrounds the pad. Surrounding the groove is a fold that represents a continuation of the lateral digital folds. $\times 252$.

9 Higher power view of the groove area from the same regenerate shown in figure 8 . The smooth surface of the pad cells is contrasted to the microvillus-covered surfaces of the cells within the circumferential canal and the irregular surface specializa. tions of the cells of lateral folds. $\times 1,062$.

10 End-on view of a 39-day spike regenerate arising from a mid forearm amputation surface. Several irregularly shaped patches of specialized pad epidermal cells (E) are scattered over the apex of the regenerate, but morphogenesis of a pad is completely lacking. $\times 63$. 

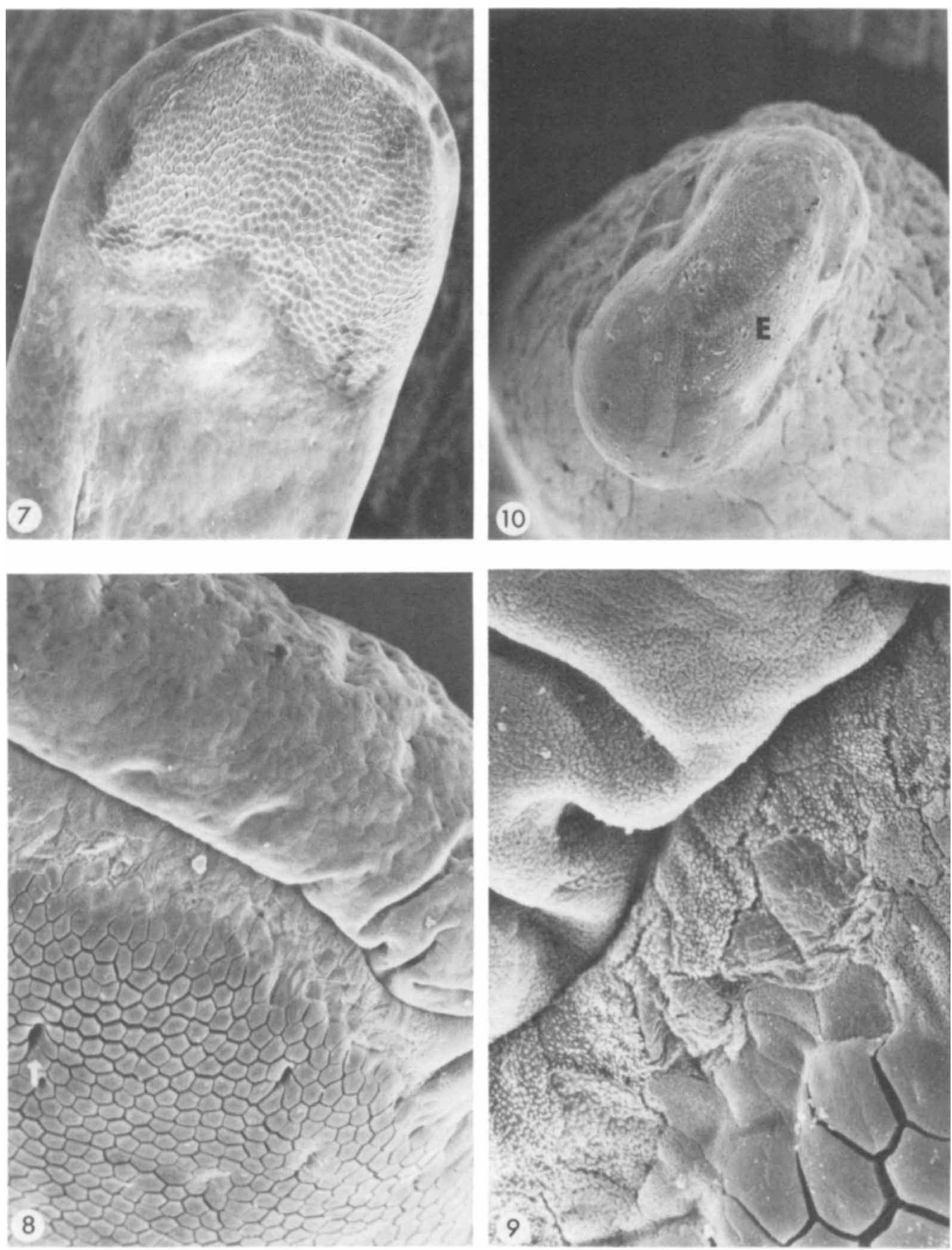